\title{
Tonsillektomi Sonrası Boy ve Kilo Değişimi Üzerine Etkili Faktörlerin Araştırılması
}

\author{
Investigation of Factors Affecting Height and Weight Change after Tonsillectomy
}

\author{
Fatih Alper AKCAN ${ }^{1}$ \\ (i) 0000-0003-2476-768X \\ Selim ULUCANLI ${ }^{2}$ \\ (1) 0000-0003-3792-5675 \\ Şengül CANGÜR ${ }^{3}$ \\ (i) 0000-0002-0732-8952 \\ İhan ÜNL $\ddot{U}^{1}$ \\ (1) 0000-0002-5649-2257
}

${ }^{1}$ Düzce Üniversitesi Tıp Fakültesi Kulak Burun Boğaz Hastalıkları AD, Düzce

${ }^{2}$ Fatih Sultan Mehmet Eğitim ve Araştırma Hastanesi Kulak Burun Boğaz Hastalıkları, İstanbul

${ }^{3}$ Düzce Üniversitesi Tıp Fakültesi Biyoistatistik ve Tıbbi Bilişim AD, Düzce

\section{Sorumlu Yazar \\ Corresponding Author \\ Fatih Alper AKCAN \\ f.akcan@yahoo.com}

Geliş Tarihi / Received : 13.11.2018 Kabul Tarihi / Accepted : 27.02.2019 Çevrimiçi Yayın Tarihi /

Available Online

\section{öz}

Amaç: $\mathrm{Bu}$ çalışmanın amacı tonsillektomi hastalarında yaş, cinsiyet, endikasyon, tonsiller grade, tonsil hacmi ve tonsil ağırlığı gibi değişkenlerin boy ve kilo gelişimi üzerine etkisinin araştırılmasıdır.

Gereç ve Yöntemler: Tüm hastaların anamnez ve muayene bulguları kaydedildikten sonra, ameliyat öncesi boy ve kilolarına bakıldı. Postoperatif 6 . ayda hastaların tekrar boy ve kiloları ölçülerek kaydedildi. Hastaların boy ve kilo gelişimleri persentil artışına göre hesaplandı. Hastaya bağlı değişkenlerin boy ve kilo gelişimine etkisi karşılaştırıldı.

Bulgular: Çalışmaya katılan toplam 45 hastanın 25'i erkek olup 20'si ise kızdır. Hastalar yaşa göre 7 yaş altı ve 7 yaş üstü olmak üzere iki gruba ayrıldı. Cerrahi endikasyona göre hastalar uykuda solunum bozukluğu (USB), rekürren tonsillit ve USB+rekürren tonsillit olmak üzere 3 grupta değerlendirildi. Hastalar tonsil büyüklüğüne göre Grade 1-2, Grade 3 ve Grade 4 olmak üzere üç grupta değerlendirildi. Hastalar tonsil hacmine göre $7 \mathrm{cc}$ altı ve üstü olacak şekilde iki gruba ayrıldı. Hastalar tonsil ağırlığına göre $7 \mathrm{gr}$ altı ve üstü olacak şekilde iki gruba ayrıldı. Bakılan hastaya bağlı değişkenlerin boy ve kilo persentil değişimi üzerine anlamlı etkisinin olmadığ görüldü.

Sonuç: Tonsillektomi sonrası gelişmeyi etkileyen hastaya bağlı faktörler açısından yapılan değerlendirmede istatistiksel olarak anlamlı sonuçlar çıkmamıştır. Bu konuda daha ayrıntılı bilgi edinebilmek için geniş hasta katılımının ve daha uzun takip sürelerinin olduğu çalışmalara ihtiyaç vardır.

Anahtar kelimeler: Tonsillektomi; büyüme-gelişme; pediatrik.

\footnotetext{
ABSTRACT

Aim: The aim of this study was to investigate the effect of parameters such as age, sex, indication, tonsillar grade, tonsil volume, tonsil weight on height and weight development in tonsillectomy patients.

Material and Methods: After the history and examination findings of all patients were recorded, preoperative height and weight were examined. At sixth postoperative month, patients' height and weight were measured and recorded. Height and weight gain of the patients were calculated according to the increase in percentile. The effects of patient dependent parameters on height and weight were compared.

Results: Of the 45 patients, 25 were male and 20 were female. Patients were divided into two groups according to age, as below 7 years and above. The patients were evaluated in 3 groups according to the indications as sleep disturbed breathing (SDB), recurrent tonsillitis and $\mathrm{SDB}+$ recurrent tonsillitis. Patients were evaluated in three groups as Grade 1-2, Grade 3 and Grade 4 according to the tonsil size. The patients were divided into two groups according to the tonsil volume, below $7 \mathrm{cc}$ and above. The patients were divided into two groups as below 7 grams and above according to tonsil weight. It was revealed that the variables related to the patients were not significant effect on the change of height and weight percentile.

Conclusion: There were no statistically significant differences in the evaluation of the factors that affected the development after tonsillectomy. In order to obtain more detailed information, large patient participation and longer follow-up periods are needed.
}

: 06.03.2019 Keywords: Tonsillectomy; growth; pediatric. 


\section{GíRiş}

Çocukluk çağında tonsilleri en çok etkileyen sorunlar, tekrarlayan enfeksiyonlar ile obstrüksiyona yol açan hipertrofilerdir. Özellikle fiziksel, psikolojik ve kognitif bozukluklara yol açabilen tıkayıcı uyku apne sendromu (TUAS) ve son dönemlerde tanımlanan üst solunum yolu rezistans sendromunu kapsayan uykuda solunum bozukluklarının önemi artmaktadır. Bu sorunlar sıklıkla çocukluk çağının en yaygın cerrahi işlemlerinden biri olan tonsillektomi ile sonuçlanabilmektedir (1).

Uykuda hormon salınımının düzenlendiği safha REM dönemidir. Adenotonsiller hastalıklarda görülen tıkayıcı uyku bozukluklarında REM dönemi kısalmaktadır (2). Kisalan REM dönemi salınan uyku hormonu (melatonin) miktarını da etkiler. Adenotonsiller hipertrofiye bağlı uyku bozukluklarında uykuda salınan büyüme hormonu genellikle düşer. Cerrahi tedavi ile uyku bozukluğu giderildiğinde genellikle uykuda salınan büyüme hormonu seviyeleri de düzelir (2). Ayrıca uykuda apne atakları olmaksızın, sadece solunum yolu direncinin artmasına bağlı hipoksi ile beraber solunum çabasının arttığı ve uykunun sıkça bölündüğü durumlarda da REM uykusunun kalite ve süresinin azalmasına bağlı büyüme hormonunun azalmış aktivitesi ve büyüme geriliği görülebilir (3).

Tonsiller hipertrofili ve kronik tonsillitli çocuklarda uyku bozukluklarının yanı sıra iştahsızlık ve yutma bozuklukları gibi nedenler ile sofradan erken kalkma gibi yakınmalar görülmektedir. Hipertrofik tonsillerin oluşturduğu obstrüksiyona bağlı olarak gelişen beslenme güçlüğü neticesinde kalori alımı azalarak erken dönemde kilo alımı azalır, geç dönemde ise boy artış hızı yavaşlayarak büyüme geriliği gelişebilmektedir (4). Kronik tonsillitli çocuklarda da kronik enfeksiyonlarda görülen şekilde büyüme gelişme geriliği oluşabilir. Kronik hastalıklar lineer büyüme üzerine çeşitli yollardan olumsuz etki eder. Bunlar iştah azalması sonucu yetersiz kalori alımı, yetersiz gıda emilimi, artmış enerji tüketimi, doku oksijenlenmesinde bozulma, kronik asidoz, protein kaybı, elektrolit dengesizliği, vitamin eksikliği, hücre içi metabolizmasının değiş̧imi, endokrin işlevlerde sekonder bozulma ve psikososyal nedenler gibi siralanabilir (4).

$\mathrm{Bu}$ çalışmada tonsiller hipertrofi ve kronik tonsillit nedeni ile tonsillektomi uygulanan olgularda hastaya bağlı faktörlerin büyüme gelişme üzerine etkilerinin araştırılması amaçlanmıştır.

\section{GEREÇ VE YÖNTEMLER}

Düzce Üniversitesi Tıp Fakültesi Hastanesi Kulak Burun Boğaz Hastalıkları Kliniği'nde Aralık 2015-Haziran 2016 tarihleri arasında kronik tonsillit ve hipertrofik tonsile bağlı uykuda solunum bozukluğu (USB) nedeni ile opere edilen 3-13 yaşları arasındaki 25'i erkek 20'si kız olmak üzere toplam 45 hasta çalışmaya alındı.

Operasyon endikasyonu konulan hastaların ailelerinden beslenme durumu, yaş ve cinsiyet gibi demografik veriler yanında, özgeçmiş ve soy geçmişe yönelik bilgileri içeren detaylı anamnez alındı. Özgeçmişinde astım, kalp veya böbrek yetmezliği, allerjik rinit, diyabet gibi kronik hastalığa sahip olan çocuklar çalışma dışı bırakıldı. Klinik anamnezde; bir yılda geçirilen tonsillit atağı sayısı öğrenildi. USB tanısı; horlama, ağzı açık uyuma, tanıklı uyku apnesi şikayetlerinin varlığı ile konuldu.

Fizik muayenede tüm hastalara otoskopik muayene, odyometri, timpanometri, anterior rinoskopi ve orofarenks muayenesi yapıld1. Ayrica anterior rinoskopide burun tıkanıklığı yapacak konka hipertrofisi ve septum deviasyonuna sahip hastalar ve nazal endoskopi yardımı ile de koanaları \%25'ten daha fazla kapatan (Grade 1) adenoid dokusu bulunan hastalar çalışma dışı bırakıldı.

Bütün hastaların operasyon öncesi boy ve kilo ölçümleri yapıldı. Hastaların ameliyat sırasında çıkarılan tonsilleri hassas terazi yardımı ile tartıldı ve 0,5 cc'ye duyarlı ölçekli beher ile tonsil hacimleri hesapland1. Postoperatif 6. ayda boy-kilo ölçümleri tekrarland1.

Tonsil ve adenoid büyüklüğünde Brodsky ve ark. (5)'nın yapmış oldukları sınıflandırma referans alınmıştır. $\mathrm{Bu}$ sınıflandırmaya göre tonsil hava yolunda görünmüyorsa tonsillerin büyüklüğü $0, \% 25$ altında hava yolu obstrüksiyonu yapıyorsa grade 1, \%25-50 arasında hava yolu obstrüksiyonu yapıyorsa grade 2, \%50-75 arasında hava yolu obstrüksiyonu yapıyorsa grade 3, \%75 ve daha fazla obstrüksiyon yapıyorsa grade 4 olarak değerlendirilmektedir.

Boy ve kilo değişimine tonsiller grade etkisi incelenirken hastalardan tonsilleri grade 1 ve 2 olanlar aynı gruba alınd1, obstrüksiyona yol açtığ 1 düşünülen grade 3 ve grade 4 tonsili olan hastalar ise ayrı ayrı olmak üzere toplam 3 gruba ayrıldı.

Boy ve kilo değişimine yaşın etkisi değerlendirilirken okul çağ́ göz önünde tutularak hastalar 7 yaş altı ile 7 yaş ve üstü olmak üzere 2 gruba ayrıldı.

Ameliyatta çıkarılan tonsillerin ağırlığının etkisi değerlendirilirken, her iki tonsil ağırlıkları toplandı ve hasta yoğunlukları dikkate alınarak 7 gr üstü ile 7 gr ve altı olmak üzere 2 gruba ayrıldı. Tonsillerin hacminin etkisi değerlendirilirken ise yine aynı şekilde hasta yoğunlukları göz önünde bulundurulmak sureti ile her iki tonsilin toplam hacimleri $7 \mathrm{cc}$ üstü ile $7 \mathrm{cc}$ ve altı olmak üzere 2 grup yapıldı.

Hastaların ameliyat öncesi ve ameliyat sonrası boy-kilo gelişimleri persentil dağılım cetveline göre hesapland. Ameliyat öncesi ve sonrası persentil farkları not edildi. Ameliyat öncesi \%3-10 boy persentilinde olan bir hastanın ameliyat sonrası boyu \%10-25 persentil olarak ölçülürse +1 persentil değişimi olarak kabul edildi.

Çalışma için, Düzce Üniversitesi Tıp Fakültesi Etik Kurul'undan (14.12.2015 tarih ve 187 nolu karar) onay alındı. Yapılan tüm işlemler öncesinde hasta ve yakınlarının aydınlatılmış onamları alındı.

\section{İstatistiksel Analiz}

Çalışmada elde edilen bulguların istatistiksel değerlendirmeleri için SPSS v.22 (Statistical Package for Social Sciences) programı kullanıldı. Çalışmadaki verilerin tanımlayıcı değerleri hesaplandı. Sürekli nicel değişkenlerin normallik varsayım kontrolü Shapiro-Wilk testi ile incelendi. Gruplar arası karşılaştırmalarda Kruskal-Wallis testi ve Mann-Whitney U testi kullanıldı. Kategorik değişkenler arasındaki fark için Pearson ChiSquare, Fisher-Freeman-Halton (post hoc bonferroni test) ve Fisher's Exact test kullanıld1. $p<0,05$ istatistiksel olarak anlamlı kabul edildi. 


\section{BULGULAR}

Çalışmaya katılan toplam 45 hastanın 25'i erkek 20'si kızdır. Boy ve kilo persentil değişimleri erkek ve kız hastalar için ayrı ayrı hesapland. Cinsiyetin boy $(p=0,664)$ ve kilo $(\mathrm{p}=0,456)$ persentil değişimi üzerine anlamlı etkisinin olmadığı görüldü.

Hastalar yaşa göre 7 yaş altı $(n=19)$ ve 7 yaş ve üstü $(n=26)$ olarak 2 gruba ayrıldı. Yaşın boy $(p=0,764)$ ve kilo $(\mathrm{p}=0,657)$ persentil değişimine etkisi olmadığ görüldü.

Cerrahi endikasyona göre hastalar USB $(n=15)$, rekürren tonsillit $(n=16)$ ve $U S B+$ rekürren tonsillit $(n=14)$ olarak 3 grupta değerlendirildi. Cerrahi endikasyonun boy $(p=0,862)$ ve kilo $(p=0,875)$ persentil değişimine etkisinin olmadığ 1 görüldü.

Hastalar tonsil büyüklüğüne göre Grade1-2 ( $n=7)$, Grade3 ( $n=11)$ ve Grade4 ( $n=27)$ olarak 3 gurupta değerlendirildi. Tonsil büyüklüğünün boy $(p=0,382)$ ve kilo $(p=0,459)$ persentil değişimine etkisi olmadı̆̆ görüldü.

Hastalar tonsil hacmine göre 7 cc altı $(n=23)$ ve 7 cc ve üstü $(n=22)$ olacak şekilde 2 gruba ayrıldı. Tonsil hacminin boy $(p=0,675)$ ve kilo $(p=0,374)$ persentil değişimine etkisi olmadığı görüldü.

Hastalar tonsil ağırlığına göre 7 gr altı $(n=20)$ ve 7 gr ve üstü $(n=25)$ olacak şekilde 2 gruba ayrıld1. Tonsil ağırlığının boy $(p=0,878)$ ve kilo $(p=0,602)$ persentil değişimine etkisi olmadığı görüldü.

Hastaya bağlı değişkenlerin ortalama ve ortanca boy ve kilo persentil değişimi üzerine olan etkileri Tablo 1'de özetlenmiştir.

\section{TARTIŞMA}

Çalışma süresince takip edilen 45 hastanın ameliyat öncesi ölçümlerinde 4 hastanın $(\% 8,9)$ boyu $<\% 3$ persentilin altında, 3 hastanın $(\% 6,7)$ ise kilosu $<\% 3$ persentilin altında kalmıştır. Ameliyat sonrası dönemde hastaların boy persentil değişimleri hesaplandığında 45 hastanın 26 'sında boy artışları olmasına rağmen persentil değişimi olmamıştır. Beş hastada ise boy değerinde düşme olmamasına rağmen persentil değerinde düşme olmuştur. On dört hastada ise persentil değerinde artma, hatta 4 hastada 2 persentil artış olmuştur. Kilo gelişimleri hesaplandığında 1 hastada kilo düşüşü ile beraber 1 persentil düşüşü, 30 hastada persentilde yükselme izlenmiştir. $\mathrm{Bu}$ hastaların beşinde 2 persentil, birinde ise 3 persentil artışı olmuştur. Boy ve kilo persentil değişimleri üzerine yaş, cinsiyet, endikasyon, tonsiller grade, tonsil hacmi ve ağırlığının bir etkisinin olmadığı görülmüştür.

Çocuklardaki uyku apnesi veya hava yolu tıkanıklığının büyük bölümünü adenoid ve tonsil hastalıkları oluşturmaktadır (6). Büyüme gelişme geriliği durumları da Amerikan Çocuk Akademisi tarafindan bu tıkayıcı solunum yolu bozukluklarının bir komplikasyonu olarak görülmüştür (7). Aynı zamanda pulmoner hipertansiyon, kor pulmonale, yüz gelişim bozuklukları, davranış bozuklukları gibi problemler de adenotonsiller hastalık nedeni ile ortaya çıkabilen durumlardır $(8,9)$.

Adenotonsiller cerrahi ile birlikte obstrüksiyonun ve kronik hastalık halinin ortadan kaldırılması büyüme ve gelişmeyi olumlu yönde etkilemektedir. Büyüme gelişmedeki bu artış; iştah ve yeme içmedeki artışa, gece tüketilen efor ve kaloride azalmaya ve büyüme hormonunun salınımındaki düzelmeye bağlanmaktadır (10).

Adenotonsiller cerrahi sonrası büyüme ve gelişme dikkat çekmektedir. Bunu bilimsel olarak ortaya koyan klinik çalışmalar bulunmaktadır. Son yıllarda yapılan bazı çalışmalarda, adenoid ve/veya tonsil hipertrofisine bağlı üst hava yolu tıkanıklığına sekonder gelişen büyüme geriliği prevalansının $\% 1$ ile $\% 46$ arasında değiştiği bildirilmektedir (11-13).

Tablo 1. Değişkenlere göre boy ve kilo persentil değişimi

\begin{tabular}{|c|c|c|c|c|c|c|c|}
\hline \multirow[b]{2}{*}{ Değişkenler } & & \multicolumn{3}{|c|}{ Boy Persentil Değişimi } & \multicolumn{3}{|c|}{ Kilo Persentil Değişimi } \\
\hline & & Ort \pm SS & $\begin{array}{c}\text { Ortanca } \\
\text { (Min-Maks) }\end{array}$ & $\mathbf{p}$ & Ort \pm SS & $\begin{array}{c}\text { Ortanca } \\
\text { (Min-Maks) }\end{array}$ & $\mathbf{p}$ \\
\hline \multirow{2}{*}{ Cinsiyet } & $\mathrm{K} 1 \mathrm{z}(\mathrm{n}=20)$ & $0,40 \pm 0,94$ & $0,0(-1,3)$ & \multirow{2}{*}{0,664} & $0,70 \pm 0,65$ & $1,0(0,2)$ & \multirow{2}{*}{0,456} \\
\hline & Erkek $(n=25)$ & $0,28 \pm 0,84$ & $0,0(-1,2)$ & & $0,88 \pm 0,88$ & $1,0(-1,3)$ & \\
\hline \multirow{2}{*}{ Yaş } & $<7$ yaş $(\mathrm{n}=19)$ & $0,44 \pm 0,84$ & $0,0(-1,2)$ & \multirow{2}{*}{0,764} & $0,72 \pm 0,55$ & $1,0(-1,2)$ & \multirow{2}{*}{0,657} \\
\hline & $\geq 7$ yaş $(n=26)$ & $0,33 \pm 0,89$ & $0,0(-1,3)$ & & $0,85 \pm 0,78$ & $1,0(0,3)$ & \\
\hline \multirow{3}{*}{ Endikasyon } & USB $(n=15)$ & $0,20 \pm 0,86$ & $0,0(-1,2)$ & \multirow{3}{*}{0,664} & $0,87 \pm 0,74$ & $1,0(0,2)$ & \multirow{3}{*}{0,456} \\
\hline & Kr. Tonsillit $(\mathrm{n}=16)$ & $0,38 \pm 0,81$ & $0,0(-1,2)$ & & $0,75 \pm 0,77$ & $1,0(-1,2)$ & \\
\hline & USB + Kr. Tonsillit $(n=14)$ & $0,43 \pm 1,02$ & $0,0(-1,3)$ & & $0,79 \pm 0,89$ & $1,0(0,3)$ & \\
\hline \multirow{3}{*}{ Tonsiller Grade } & Grade $1-2(n=7)$ & $0,14 \pm 0,38$ & $0,0(0,1)$ & \multirow{3}{*}{0,382} & $1,00 \pm 0,58$ & $1,0(0,2)$ & \multirow{3}{*}{0,459} \\
\hline & Grade $3(n=11)$ & $0,45 \pm 1,04$ & $0,0(-1,2)$ & & $0,64 \pm 0,81$ & $1,0(-1,2)$ & \\
\hline & Grade $4(n=27)$ & $0,33 \pm 0,92$ & $0,0(-1,3)$ & & $0,81 \pm 0,83$ & $1,0(0,3)$ & \\
\hline \multirow{2}{*}{ Tonsil hacmi } & $\leq 7 \mathrm{cc}(\mathrm{n}=23)$ & $0,26 \pm 0,75$ & $0,0(-1,2)$ & \multirow{2}{*}{0,675} & $0,86 \pm 0,62$ & $1,0(0,2)$ & \multirow{2}{*}{0,394} \\
\hline & $>7 \mathrm{cc}(\mathrm{n}=22)$ & $0,40 \pm 1,00$ & $0,0(-1,3)$ & & $0,72 \pm 0,93$ & $1,0(-1,3)$ & \\
\hline \multirow{2}{*}{ Tonsil ağırlığı } & $\leq 7 \mathrm{gr}(\mathrm{n}=20)$ & $0,40 \pm 0,99$ & $0,0(-1,3)$ & \multirow{2}{*}{0,878} & $0,85 \pm 0,67$ & $1,0(0,2)$ & \multirow{2}{*}{0,602} \\
\hline & $>7 \mathrm{gr}(\mathrm{n}=25)$ & $0,28 \pm 0,79$ & $0,0(-1,2)$ & & $0,76 \pm 0,87$ & $1,0(-1,3)$ & \\
\hline
\end{tabular}

Ort \pm SS: ortalama \pm standart sapma, Min: minimum, Maks: maksimum, USB: uykuda solunum bozukluğu, Kr: Kronik 
Ahlqvist-Rastad ve ark. (11) üst hava yolu tıkanıklığına bağlı şikayetleri olan, ek medikal problemleri olmayan 122 hastayı değerlendirdikleri çalışmada; tonsillektomi uygulamasından ortalama 12 ay sonra 64 hastada (\%52), boy ve kiloda anlamlı artış olduğunu göstermişlerdir. Araştırmacılar tonsillektomi sonrası anlamlı boy ve kilo artışını, stres hormonlarının salınımının azalmasına bağlı olarak metabolizma üzerindeki stresin azalmasına, katabolik etkinin azalması ve anabolik etkinin belirginleşmesine bağlamışlardır.

Yapılan çalışmaların çoğunda, adenotonsil hipertrofisine bağlı üst hava yolu tıkanıklığının büyüme ile ilişkisinin araştırıldığı görülmektedir. Buna karşın yineleyen/kronik enfeksiyonun, büyüme ile ilişkisine yönelik yapılan çalışma sayısı ise daha azdır (12-15). Çalışmamızda bu durum göz önünde bulundurulmuştur. Endikasyona göre gruplar arasında büyüme açısından fark olmadığ görülmüştür.

Büyümenin değerlendirilmesinde kullanılan bu parametrelerde değişiklik saptanmasının en az 6 aylık bir süre sonunda ortaya çıkabileceği göz önünde bulundurulmalidir (16).

Aydoğan ve ark. (3) da adenotonsiller cerrahi yapılan 38 hastada ameliyat öncesi kilo değerlerinde hiç bir hastada normal sınırların altında değer saptanmazken, sadece bir çocukta $(\% 2,6)$ boyun normal değerlerin altında seyrettiği görülmüştür. $\mathrm{Bu}$ çalışmada hastalar puberte öncesi dönemden seçilmiştir. Buna karşın Hodges ve ark. (17) ise üst hava yolu tıkanıklığına bağlı şikayetler nedeniyle adenotonsiller cerrahi uyguladıkları çocukların, ameliyat öncesi kilo persentillerinin normalin altında olduğunu ve ameliyat sonrası kilo persentillerinde ortalama 2,5 ay içinde anlamlı artış olduğunu bildirmişlerdir. Çalışma sonunda yazarlar büyüme geriliği olan çocuklarda, erken dönemde uygulanacak adenotonsiller cerrahi ile çocukların genel durumunda iyileşme ve kilo alımında artış sağlanabileceğini ileri sürmüşlerdir.

Williams ve ark. (10) ağır üst hava yolu tıkanıklığı semptomları bulunan 41 çocuğu içeren retrospektif çalışmalarında, operasyondan ortalama 11,6 ay sonra, boy ve kilo ölçümlerini ameliyat öncesi ölçümlerle karşılaştırmışlar ve 31 hastanın (\%75) kilo persantillerinde anlamlı artış saptayarak, tıkayıcı uyku bozukluklarının suboptimal büyüme ile ilişkili olduğunu ve tedavi ile büyümenin hızlanacağını bildirmişlerdir.

Birçok çalışmada cerrahi sonrası, çocuklarda boy ve kilo da istatistiksel olarak anlamlı artışlardan bahsedilmektedir (18-20). Genellikle kilo değerlerinin boya göre daha sık gelişim gösterdiği bildirilmiştir. Yine bu çalışmalarda gelişimin nedeni sıklıkla uykunun düzene girmesi ile artan büyüme hormonu salınımı, iştah artışı gibi nedenlere bağlanmıştır.

\section{Kisitlamalar}

Çalışmamızda takip süresinin kısa olması ve hasta sayısının az olması en önemli kısıtlayıcı faktörler olarak öne çıkmaktadır. Ayrıca hastalarda uykuda solunum bozukluğu tanısının polisomnografi ile değil anamnezle konulmuş olması bir diğer kısıtlayıcı faktördür.

\section{SONUÇ}

Tonsillektomi sonrası gelişmeyi etkileyen hastaya bağlı faktörler (yaş, cinsiyet, endikasyon, tonsiller grade, tonsil hacmi ve ağırlı̆̆ı) açısından yapılan değerlendirmede istatistiksel olarak anlamlı sonuçlar çıkmamıştır. Bu konuda daha ayrıntılı bilgi edinebilmek için geniş hasta katılımının olduğu çalışmaların yapılması gerekmektedir.

\section{KAYNAKLAR}

1. Ramos SD, Mukerji S, Pine HS. Tonsillectomy and adenoidectomy. Pediatr Clin North Am. 2013;60(4):793-807.

2. Goldstein SJ, Wu RH, Thorpy MJ, Shprintzen RJ, Marion RE, Saenger P. Reversibility of deficient sleep entrained growth hormone secretion in a boy with achondroplasia and obstructive sleep apnea. Acta Endocrinol (Copenh). 1987;116(1):95-101.

3. Aydogan M, Toprak D, Hatun S, Yüksel A, Gokalp AS. The effect of recurrent tonsillitis and adenotonsillectomy on growth in childhood. Int $\mathrm{J}$ Pediatr Otorhinolaryngol. 2007;71(11):1737-42.

4. Brouillette RT, Morielli A, Leimanis A, Waters KA, Luciano R, Ducharme FM. Nocturnal pulse oximetry as an abbreviated testing modality for pediatric obstructive sleep apnea. Pediatrics. 2000;105(2):40512.

5. Brodsky L, Moore L, Stanievich JF. A comparison of tonsillar size and oropharyngeal dimensions in children with obstructive adenotonsillar hypertrophy. Int $\mathrm{J}$ Pediatr Otorhinolaryngol. 1987;13(2):149-56.

6. Richardson MA. Sore throat, tonsillitis, and adenoiditis. Med Clin North Am. 1999;83(1):75-83.

7. Farber JM. Clinical practice guideline: diagnosis and management of childhood obstructive sleep apnea syndrome. Pediatrics. 2002;110(6): 1255-7.

8. Aji DY, Sarığlu A, Sever L, Arısoy N. Pulmonary hypertension due to chronic upper airway obstruction: a clinical review and report of four cases. Turk $\mathrm{J}$ Pediatr. 1991;33(1):35-41.

9. Wilkinson AR, McCormick MS, Freeland AP, Pickering D. Electrocardiographic signs of pulmonary hypertension in children who snore. Br Med J (Clin Res Ed). 1981;282(6276):1579-81.

10. Williams EF 3rd, Woo P, Miller R, Kellman RM. The effects of adenotonsillectomy on growth in young children. Otolaryngol Head Neck Surg. 1991;104(4):509-16.

11. Ahlqvist-Rastad J, Hultcrantz E, Melander $H$, Svanholm H. Body growth in relation to tonsillar enlargement and tonsillectomy. Int $\mathrm{J}$ Pediatr Otorhinolaryngol. 1992;24(1):55-61.

12. Vontetsianos HS, Davris SE, Christopoulos GD, Dacou-Voutetakis C. Improved somatic growth following adenoidectomy and tonsillectomy in young children. Possible pathogenetic mechanisms. Hormones (Athens). 2005;4(1):49-54.

13. Kiris M, Muderris T, Celebi S, Cankaya H, Bercin S. Changes in serum IGF-1 and IGFBP-3 levels and growth in children following adenoidectomy, tonsillectomy or adenotonsillectomy. Int $\mathrm{J}$ Pediatr Otorhinolaryngol. 2010;74(5):528-31.

14. Barr GS, Osborne J. Weight gain in children following tonsillectomy. J Laryngol Otol. 1988;102(7):595-7.

15. Conlon BJ, Donnelly MJ, McShane DP. Tonsillitis, tonsillectomy and weight disturbance. Int $\mathrm{J}$ Pediatr Otorhinolaryngol. 1997;42(1):17-23.

16. Yılmaz MD, Hoşal AS, Oğuz H, Yordam N, Kaya S. The effects of tonsillectomy and adenoidectomy on 
serum IGF-I and IGFBP3 levels in children. Laryngoscope 2002;112(5):922-5.

17. Hodges S, Wailoo MP. Tonsillar enlargement and failure to thrive. $\mathrm{Br}$ Med $\mathrm{J}$ (Clin Res $\mathrm{Ed}$ ). 1987;295(6597):541-2.

18. Koycu A, Aydin E, Tulgar Kinik S. Changes in body composition and growth pattern after adenotonsillectomy in prepubertal children. Int $\mathbf{J}$ Pediatr Otorhinolaryngol. 2016;81:46-50.
19. Lewis TL, Johnson RF, Choi J, Mitchell RB. Weight gain after adenotonsillectomy: a case control study. Otolaryngol Head Neck Surg. 2015;152(4):734-9.

20. D'Esposito CF, Farhood Z, Baker AB, Nguyen SA, LaRosa AC, Lal C, et al. Assessment of weight gain following adenotonsillectomy in children with Down syndrome. Int $\mathrm{J}$ Pediatr Otorhinolaryngol. 2017;100:103-6. 